\title{
A PRELIMINARY STUDY OF PROOF OF CONCEPT PRACTICES AND THEIR CONNECTION WITH INFORMATION SYSTEMS AND INFORMATION SCIENCE
}

\author{
Antonio Jose Rodrigues Neto \\ Faculty of Letters, \\ University of Coimbra, Portugal. \\ neto@student.uc.pt
}

\author{
Maria Manuel Borges \\ Faculty of Letters, \\ University of Coimbra, Portugal. \\ $\underline{\text { mmb@fl.uc.pt }}$
}

\author{
Licinio Roque \\ Dep. of Informatics Engineering, \\ University of Coimbra, Portugal. \\ lir@dei.uc.pt
}

\begin{abstract}
In this study, we have identified that a Proof of Concept can be characterized as a research practice and instrument of knowledge creation, based on a set of activities that are applied to the study and understanding of certain objects by the actors involved. In Information Systems Development, we have characterized a Proof of Concept as a system that creates sociotechnical phenomena and, with the aim of understanding these phenomena, we use the Context Engineering approach. Context Engineering represents the relationship between a set of essential movements in a new framework of activities of Information Systems Development. Furthermore, we highlight Information Science, which allows us to study in formal and rigorous ways the processes, techniques, conditions, and effects that are entailed in improving the efficacy of information, which is used for a range of purposes related to individual, social and organizational needs, as well as new methods of scientific communication. To our knowledge, and following a review of the literature, there is a lack of studies combined with gaps in the knowledge of Proof of Concept practices. The misunderstanding of these practices may strengthen the probability of compromising the reliability, reproducibility, and reusability of the knowledge consumed or constructed in a Proof of Concept, which may affect its appropriate utilization by the organizations, their actors, or communities of practice. In this context, this paper aims to promote a preliminary study of the state-of-the-art scientific knowledge and to contribute to the body of published literature on Proof of Concept practices.
\end{abstract}

\section{CCS Concepts}

Information systems $\rightarrow$ Information retrieval

Permission to make digital or hard copies of all or part of this work for personal or classroom use is granted without fee provided that copies are not made or distributed for profit or commercial advantage and that copies bear this notice and the full citation on the first page. Copyrights for components of this work owned by others than the author(s) must be honored. Abstracting with credit is permitted. To copy otherwise, or republish, to post on servers or to redistribute to lists, requires prior specific permission and/or a fee. Request permissions from Permissions@acm.org.

TEEM'18, October 24-26, 2018, Salamanca, Spain

(C) 2018 Copyright is held by the owner/author(s). Publication rights licensed to ACM.

ACM ISBN 978-1-4503-6518-5/18/10...\$15.00

https://doi.org/10.1145/3284179.3284226

\section{Keywords}

Proof of Concept, Information Systems Development, Context Engineering, Information Science

\section{ACM Reference format:}

Antonio Jose Rodrigues Neto. 2018. A PRELIMINARY STUDY OF PROOF OF CONCEPT PRACTICES AND THEIR CONNECTION WITH INFORMATION SYSTEMS AND INFORMATION SCIENCE. In Proceedings of Sixth International Conference on Technological Ecosystems for Enhancing Multiculturality (TEEM'18). ACM, 5 pages. DOI: https://doi.org/10.1145/3284179.3284226

\section{INTRODUCTION}

A Proof of Concept (POC) is a research practice that is performed by organizations. A POC serves as an instrument of knowledge construction in the study and understanding of certain objects (i.e., artifacts and phenomena). In other words, a POC is a research practice which has a set of activities (i.e., actions, movements, analyses, simulations, techniques, tests, among others) for the assessment, understanding, validation, and exploration of, and the learning about objects in a given area of knowledge.

A POC is used "to prove a concept through a practical model" [45], with the aim of promoting knowledge of the objects under study. According to Kendig [23], "the notion of proof of concept research is framed in terms of a particular kind of research that provides justification in practice of the potential transportability of knowledge acquired through the experimental test case".

A well-organized and executed POC enables organizations to analyze, understand, validate and learn; or in other terms, to produce and gain certain knowledge. The lack of characterization and a conceptual model of POC practices may impact the 'knowledge of the practice', thus increasing the probability of compromising the reliability, reproducibility and reusability of the knowledge in a POC, which may affect the proper utilization of that knowledge by the organizations, their actors, or communities of practice [47-49].

Simplistically, a POC can be characterized as a 'system' that has a set of activities which has, as input, a set of questions (information) and as output, potential answers corresponding to a certain knowledge. Hence, a POC is a 'practice' for knowledge construction based on a theoretical-practical foundation of 
research, which seeks to extend the knowledge pertaining to the objects under study.

Checkland [8,9] presents a generic description of systems, characterized as "an entity that receives some inputs and produces some outputs", a definition that supports the foundation and framework of our study of the POC practices in the scope of Information Systems Development (ISD).

As a starting point in our research proposal, we formulate the following hypothesis: The lack of characterization and a model of POC practices compromises the reliability, reproducibility, and reusability of the knowledge consumed or constructed in a POC. Furthermore, it is not possible to reflect on or to understand how to present and communicate that knowledge to be utilized appropriately by the organizations, their actors, or communities of practice.

We present a preliminary study of POC practices within the scope of ISD and having the perspective of Context Engineering [2,33-35] that "represents the relationship between a set of essential movements in a new framework of activities of ISD, visualizing the development as a socio-technical phenomenon" and their connection to Information Science. With the latter, we particularly act in accordance with a study of Rayward [32], whereby Information Science aims "to study in formal and rigorous ways the processes, techniques, conditions, and effects that are entailed in improving the efficacy of information, variously defined and understood, deployed and used for a range of purposes related to individual, social and organizational needs".

We highlight the reflections on Information Systems in the work of Allen [1] and the interdisciplinarity of Information Science in the work of Wersig [50]. Allen defines an Information System as "a linked and related system of entities (including one or more information devices) that provides access to one or more bodies of knowledge and acts as a mechanism through which individuals can inform other individuals or through which they themselves can become informed".

Saracevic [36-38] highlights the problem proposed by Information Science as making more accessible a collection of knowledge, while not caring whether the activity that deals with these issues is called Information Science or whether any other terminology is adopted, since the problems are focused on human terms rather than on technological terms.

In this context, this paper aims to contribute to a preliminary study of the POC practices and their connection with Information Systems and Information Science, with the further aims of contributing to the characterization, and also providing a conceptual model, of these practices.

\section{METHODOLOGY}

In response to the proposed objective in the present study, a review of the literature was undertaken. The bibliography research was based on the databases provided by the University of Coimbra (UC, Portugal), the Scientific Repository of Open Access of Portugal (RCAAP), and Google Scholar.
The terms used for information retrieval were "Proof of Concept", "Information Systems", and "Information Science" using both languages of "English" and "Portuguese". In accordance with the work of Neto, Borges and Roque [26,27], at a later stage in our research "a cross-sectional analysis was performed on the collected articles, based on the abstract, keywords, introduction and conclusion, to determine and to select the relevant documents of interest for the study". After finishing the collection and selection of the bibliography, "an indepth analysis of the fundamental concepts was performed with the aim to reflect on all the contents in order to respond to the objectives outlined for this study" [26,27].

\section{RESULTS}

The Proof of Concept (POC) has several interpretations and terminological definitions within the body of scientific literature, such as a study, an idea, a method, a technique, a process, a set of tests, an experimental practice, among others, while not presenting a consensus in its definition.

After an in-depth analysis of the different terminological definitions of Proof of Concept (POC), we understand a Proof of Concept (POC) to mean: a research practice that is characterized by a set of activities [movements] [practices] that are carried out with the application of certain knowledge by the different actors involved in its execution.

The term 'practice', according to Schatzki et al. [40], refers to "embodied, materially mediated arrays of human activity that are centrally organized around a shared practical understanding". According to practice theory (particularly regarding the work of Schatzki [39]), "a practice consists of particular sets of activities [movements] or basic actions, which at a lower level of abstraction may constitute practices as such, where a basic action can be performed simultaneously in multiple contexts and can constitute multiple actions" [22].

Thus, in our study, we have adopted the term 'practice' in accordance with the works of Isabelle et al. [21] and Schön [42]: "We define practices as both what people do in situations and the way they do it [in those situations]. Practices are knowing in action (Piaget, 1974), that is, [practices are] dispositions enacted in specific situations (Bourdieu, 1990)" [21]. Furthermore, Schön notes "I offer an approach to epistemology of practice based on a close examination of what some practitioners-architects, psychotherapists, engineers, planners, and managers-actually do" [42]. Thus, we understand that the definitions cited support our understanding of what comes to be a POC.

Although, according to Gradvohl [18], a POC is generally an incomplete realization of an idea in order to demonstrate what is feasible, i.e., evidence that this idea is feasible and also evidence that this is a "learning tool" [4].

Based on a review of the literature, we identified that there is a lack of studies, combined with gaps in the knowledge, on POC practices. In other words, it was not possible to identify in the scientific literature: studies about POC practices, their characterization and a conceptual model, and the importance and impact of Information Science on these practices. 
However, we have identified many studies in different areas of scientific knowledge within the body of literature that use a POC to support their research [5,7,19,25,28,41,43-46]. Notwithstanding the aforementioned, we did find a potential standard in the existence of common elements on these scientific studies, which use a POC as a support tool in their research process.

Following a more detailed analysis of the collected data, we identified at least seven common elements in the scientific studies that use a POC in their research process. The identified elements were: Case Studies, Actors, Purpose of the Study, Scientific Domain, Actions, Hypotheses, and Results (Figure 1).

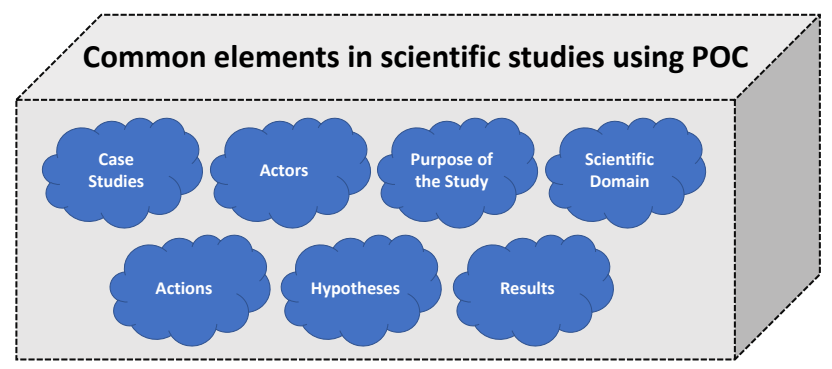

Figure 1: Common elements in scientific studies using POC.

The definitions and approaches of ISD presented by Hirschheim, Klein and Lyytinen [20] contribute to the foundation of our investigation in the scope of Information Systems as "a technological system that manipulates, stores, and disseminates symbols (representations) that have, or are expected to have, relevance and an impact on socially organized human behavior".

Nunamaker, Chen and Purdin [29] contribute to the foundation of our study of POC practices in the context of Information Systems, particularly in ISD. In their study entitled "Systems development in Information Systems Research", the authors consider that 'research' generally follows a pattern consisting of "problem, hypothesis, analysis and arguments", similar to a POC where the same approach is equivalent to a "proof-by-demonstration" [29].

In another perspective, Orlikowski [30] in her study called "The Duality of Technology", demonstrates a view on Information Systems and technology that strengthen "investigations of the interaction between technology and organizations that seek patterns across certain contexts [in POC practices] and certain types of technology, rather than abstract, deterministic relationships that transcend settings, technologies, and intentions". The same author presents the technology as "physically constructed by actors [POC practitioners] working in a given social context [POC practices], and technology is socially constructed by actors through the different meanings they attach to it and the various features they emphasize and use".

Orlikowski and Iacono [31] also discuss the lack of theories about artifacts in the field of Information Technology (IT) and their interdependence in different contexts, and their practices, which we understand to be applicable as well to the study of POC practices.

Roque, Almeida and Figueiredo [34] present the Context Engineering and discuss the importance of the context as a fundamental theme in engineering and design and its complex set of conditions to be studied and understood in the modeling and development of artifacts. The contribution of Context Engineering [35] to this study of POC practices aims to (1) frame ISD activities [POC practices], supported by the relationship between context and activity mediators [communities of practice], associated with that context; (2) gain an understanding of ISD activities [POC practices] in a framework, viewing the development [in a POC] as a socio-technical phenomenon; and (3) address the contextuality in ISD [POC practices] as a key to the realization of free-form movements.

Also, the Context Engineering [35] presents as the proactive co-evolution of context and artifacts, both objects of development practice, with a set of activities [movements]: Diagnostic, Innovation, Creation, Evaluation, Adaptation, Generalization, and Consolidation. The Consolidation movement represents "the consolidation phase of the new form of activity [movement] as suggested in our adaptation of the Expansive Learning Cycle (Engeström, 1987). This phase represents the process of adaptation that occurs after the generalization of the new instruments when a new form of activity emerges through an interaction with the neighboring activities in the target context" [33].

Further, the Context Engineering [2,33-35] (Figure 2) is centered on a conceptual framework, which represents the relationship between a set of essential movements in a new form of ISD framing development, aiming to develop a sketch of the problems, centered on the context, as a fundamental part in the provisioning of resources for interpretation and understanding of these phenomena (i.e., problems, activities, or practices), where we understand to be essential in the execution of a POC.

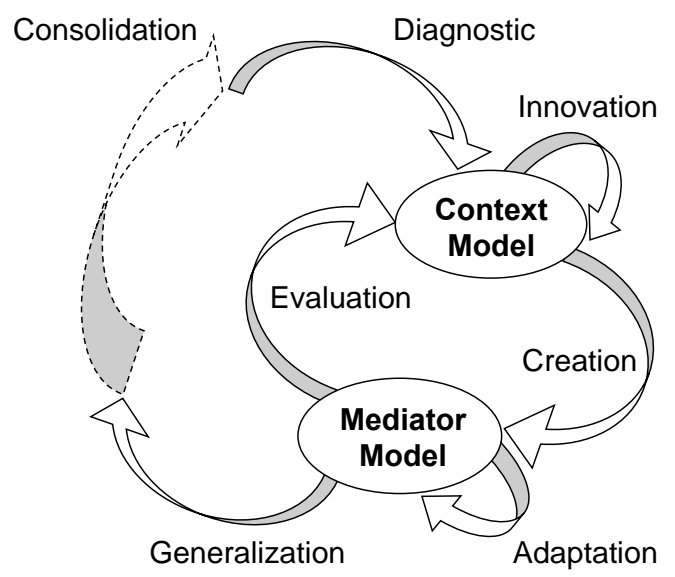

Figure 2: Context Engineering framework [35]. 
Roque [35] notes that the design activities [movements] are "the essential character of any design activity, the 'conversation' that the professional establishes with the situation and with engineering as a movement-testing experience". We also understand this interpretation to be suitable in POC practices and with respect to their community of practice (i.e., POC practitioners, participants, organizations, different actors, among others).

We also highlight the importance of Schön's work "The Reflective Practitioner: How Professionals Think in Action, a reflection on practice" [42]. Schön emphasizes the importance and the need for reflection on the action, and in the context of this action, on the part of the practitioners, for the definition and adjustment of their processes with respect to the objectives to be achieved, a reflection that we have identified to be applicable to POC practices.

Also, we have identified that Activity Theory [12,13,15-17,24] plays important role in the study of POC practices, as a "philosophical and cross-disciplinary framework for studying different forms of human practices as development processes, on both individual and social levels, interlinked at the same time" [24]. Also, according to Engeström, the Activity Theory is a "new framework aimed at transcending the dichotomies of micro- and macro-, mental and material, observation and intervention in analysis and redesign of work" [13-15,17].

In the perspective of a POC, the activities [movements] are intended to acquire certain knowledge of one or more objects (i.e., artifacts) of interest to organizations and their actors. These organizations might use a set of movements which are present in the POC in aiming to achieve a certain result, whether or not they are inserted into a given community with its own characteristics, such those of social and technological.

Based on these characteristics, it becomes interesting and important to analyze and study the application of certain movements that are present in the execution of activities by the communities of practice [47-49], which somehow are being built and represented during a $\mathrm{POC}$ or from the interaction with a different POC (i.e., POC X and POC Y) and their elements, such as: Artifacts, Subjects, Practices, Communities of Practice, Objects, and Knowledge (Figure 3) [14].

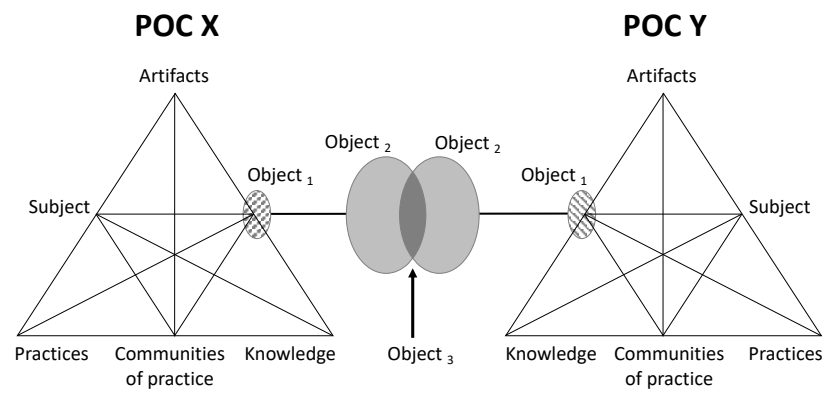

Figure 3: Two interacting POC (activity systems) for the third generation of activity theory - adapted from [14].
In a different perspective, Corbett's work "On Being an Elephant in the Age of Oblivion: Computer-based information systems and organisational memory" [11], highlights the importance of organizational memory and the dominance of individual-based psychological memory models, where we identify the importance of Information Systems and the connection with Information Science with respect to the study of POC practices.

A memory is a function that "benefits humans by allowing the use of past experiences in solving new problems. It provides individuals with a snapshot of personal experiences, enabling ways to anticipate events. For this, memory is based on acquisition, storage, retrieval and information use skills" [3].

According to Corbett, an organizational memory is a "generic concept used to describe the processes of acquisition, retention, maintenance, research and retrieval of knowledge within an organization" [11].

Corbett [11] emphasizes the importance of interpretation problems that inevitably arise in the design and use process, where we reflect and question the relevance of the understanding and characterization of POC practices and their potential influence on the organizational memory and the memory of its individuals.

A lack and misinterpretation of the knowledge of POC practices, as well as a lack of analysis, reflection, and understanding of these practices in different contexts (i.e., social and technological), may increase the probability of compromising and manipulating the organizational memory, the memory of individuals and the collection of knowledge fragments of an organization [11], which we describe as the domino effect in POC practices.

We can exemplify the potential domino effect in POC practices using the study of Neto and Da Fonseca [28], which is a comparative performance study between two communication data protocols in storage systems, where the study is centered on a POC for the construction of a comparative analysis and the presentation of the final results.

Depending on a simple context change or the practices adopted in the study of Neto and Da Fonseca [28] (i.e., the change of a social or technological context in the work of the POC practitioner; the change of any artifacts or phenomena; or even the understanding, reflection, characterization, and execution of these tests by different actors in POC practices), could both compromise and influence the comprehension of all the objects involved in the study, as well as the results, regardless of their human or non-human nature, potentializing the domino effect for all components of the system (i.e., actors, networks, systems, knowledge, among others) and potentially the future works based on this comparative study. This means that the simple change of context, or the lack of understanding and characterization of these practices, increases the probability of changing, in a positive or negative way, their understanding and execution, potentially contributing to knowledge creation and dissemination (efficient or deficient) by the POC, to organizations, their actors, or communities of practice. 
According to Almeida, "Individuals, members of an organization [communities of practice], retain information from their own direct experiences [practices]. This information can be retained in the memory of the individual or, more subtly, in their structures of beliefs and values" [3].

We understand that the non-definition of a model of POC practices, even as a conceptual framework, as well as the lack of the characterization of these practices, can intensify and strengthen the difficulty to reflect on and comprehend these practices, thus increasing the probability for inefficient knowledge creation and dissemination, or knowledge that is incorrect and repetitively so, to organizations, their actors, or communities of practice.

Information Systems, as well as POC, not only "store information, but can influence and change (sociocultural) interactions that define organizational institutions, as well as their processes that enable the mobilization of these organizational resources" [11]. As a result, we identify the importance of Information Systems and Information Science with respect to our study of Proof of Concept (POC) practices.

According to Le Coadic [10], Information Science has "identified and delimited its object of study and its fundamental research problems: [Information Science is] a study of the general properties of information (nature, genesis and effects), processes and systems of construction, communication and use of this information". Furthermore, Saracevic [36-38] describes Information Science as "a field of professional practice and scientific inquiry addressing the effective communication of information and information objects, particularly knowledge records, among humans in the context of social, organizational, and individual need for and use of information".

Machlup and Mansfield, as cited in [32], describe Information Science as a narrow discipline and present various research projects which Information Science can encompass, such as "Studies of patterns of communication among scientists and scholars (i.e., co-citation analysis); modeling and computer simulation of information systems and networks; studies of the character and behavior of users of information systems and services; studies of human factors involved in the design of man/machine systems, and so on". Also, Hayes, as cited in [32], proposes that Information Science "is the study of the means by which organizations (which we call 'information systems') process recorded symbols to meet their defined objectives".

In this way, we present our preliminary results on the study of Proof of Concept (POC) practices, with the aim of contributing to the reflection on, and knowledge of, the practice - which is actually a study within the scope of ISD with the goals of characterizing and proposing a conceptual model of these practices from the perspective of Context Engineering, viewing their development as a socio-technical phenomenon. The further aim is to contribute to the reflection and understanding of these practices by the actors involved, as well as a reflection on the implications of these practices with respect to organizations and their actors from the perspective of Information Science.
Thus, we highlight our study as a research proposal in terms of an arrangement/situation which involves some reciprocal obligation or mutual action (i.e., a 'two-way street') in the search for knowledge in the relationship of Context Engineering with regards to Information Science, a relationship that we consider essential to the study of Proof of Concept (POC) practices.

\section{CONCLUSIONS}

A Proof of Concept (POC) is a research practice and can be characterized as an instrument of knowledge construction in the submission of objects (i.e., artifacts and phenomena) of any nature to a set of activities, in order to contribute to the understanding and knowledge of these objects under study, in the development and adoption of new products or technologies by organizations and their actors [6,23].

As aforementioned, we identified a lack of studies on POC practices and their characterization, as well as studies on how to acquire, present and document the knowledge used or produced in a POC to organizations, their actors, or communities of practice. Notwithstanding this lack, we have identified a POC as a 'system' that somehow produces some knowledge on, and the importance of, the connection of ISD, more specifically within Context Engineering [2,33-35] and Information Science [32], in order to develop a study of these practices and their impact to organizations, their actors, or communities of practice.

We have identified that Information Science [32] has a fundamental role in our research proposal in the relationship with Context Engineering [35]. We aim to provide a reflection on the potential implications of these practices towards organizations, as well as communities of practice, whether they be related to information management or knowledge management, that involve improving the effectiveness of information, among other aspects. Thus, we conclude that it is non-desirable to establish a reflection of these implications without a systematic and proper study of the characterization of these practices and a proposal of their conceptual model, supported by the theoretical framework of Context Engineering and its connection with Information Science.

We understand that the complete set of activities, including organizations, actors (human, non-human, or both), communities of practice, systems, among others, associated with the context can influence a POC by potentially effecting (positively or negatively) the knowledge created and disseminated to organizations and their actors, which translates to domino effect.

Therefore, we emphasize the importance of characterizing the POC practices, and therefore forward a proposal of their conceptual model in aiming to contribute not only to the knowledge of POC practices, but also the knowledge management of these practices to organizations, their actors, or communities of practice, where we also identify Information Science, which plays an important role in the process of transforming information into knowledge, which is essential in the Proof of Concept (POC) practices. 


\section{REFERENCES}

[1] Bryce Allen. 1996. Information tasks: toward a user-centered approach to information systems. Academic Press, San Diego, USA

[2] Ana Almeida and Licinio Roque. 2000. Simpler, Better, Faster, Cheaper, Contextual: Requirements Analysis for a Methodological Approach to Interaction Systems Development. In Proceeding of the 8th European Conference on Information Systems - ECIS 2000 .

[3] Maurício Barcellos Almeida. 2006. Um modelo baseado em ontologias para representação da memória organizacional. Universidade Federal de Minas Gerais. DOI:https://doi.org/10.1590/S1413-99362006000300013

[4] Renato Manzan de Andrade, Reginaldo Arakaki, and Jorge Luis Risco Becerra 2006. O uso de provas de conceito como ferramenta para gestão de aprendizado de arquitetura de software. Int. Conf. Inf. Syst. Technol. Management. 3, 2006 (2006), 284-300.

[5] Ponrathi Athilingam, Bradlee A Jenkins, Heather Zumpano, and Miguel A Labrador. 2018. Mobile technology to improve heart failure outcomes: A proof of concept paper. Applied Nursing Research. 39, October 2017 (2018), 26-33. DOI:https://doi.org/10.1016/j.apnr.2017.10.018

[6] James D. Barnes, Robin D. Katzer, Dora Potluri, and M. Jeffrey Stone. 2009 DEMONSTRATING PROOF OF CONCEPT OF A PROJECT WITH REOUIREMENTS COMPONENT PROVIDING WEIGHTS ON IMPORTANCE AND TRACKING WITH USE CASES. United States Patent, United States of America.

7] Ricardo Matos Chaim, Edgard Costa Oliveira, and Aleteia Patricia F. Araujo. 2017. Proof of concept think! EHR platform. In2017 12th Iberian Conference on Information Systems and Technologies (CISTI), 1-7. DOI:https://doi.org/10.23919/CISTI.2017.7975850

[8] Peter Checkland. 1981. Systems Thinking, Systems Practice. Wiley, Chichester.

[9] Peter Checkland. 1999. Systems Thinking, Systems Practice: includes a 30-year retrospective. Wiley, Chichester.

[10] Yves-François Le Coadic. 2004. A Ciência da Informação (2. ed. rev ed.). Briquet de Lemos, Brasília.

[11] J. Martin Corbett. 2000. On being an elephant in the age of oblivion: Computerbased information systems and organisational memory. Information Technology \& People. 13, 4 (2000), 282-297. DOI:https://doi.org/10.1108/09593840010359482

[12] Yrjö Engeström. 1987. Learning by Expanding: An activity-theoretical approach to developmental research. DOI:https://doi.org/10.1016/j.intcom.2007.07.003

[13] Yrjö Engeström. 2000. Activity theory as a framework for analyzing and

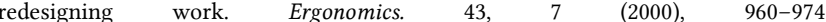
DOI:https://doi.org/10.1080/001401300409143

[14] Yrjö Engeström. 2001. Expansive Learning at Work: toward an activity theoretical reconceptualization. Fournal of Education and Work. 14, 1 (2001), 133156. DOI:https://doi.org/10.1080/13639080123238

[15] Yrjö Engeström. 2008. The Future of Activity: A Rough Draft. In Internationa Society for Cultural and Activity Research (ISCAR).

[16] Yrjö Engeström. 2016. Studies in Expansive Learning: Learning What is Not Yet There. Cambridge University Press, Cambridge. DOI:https://doi.org/10.1017/CBO9781316225363

[17] Yrjö Engeström, Reijo Miettinen, and Raija-Leena Punamäki. 1999. Perspectives on Activity Theory. Cambridge University Press, Cambridge. DOI:https://doi.org/DOI: 10.1017/CBO9780511812774

[18] André Leon Sampaio Gradhvohl. 2005. TV Interativa baseada na Inclusão de Informações Hipermídia em Vídeos no Padrão MPEG. Universidade de Campinas.

[19] Sergio Hirata. 2010. Análise comparativa das arquiteturas de armazenamento NAS e SAN para suporte a uma aplicação de entrada de pedidos. Universidade de São Paulo.

[20] Rudy Hirschheim, Heinz K Klein, and Kalle Lyytinen. 1996. Exploring the intellectual structures of information systems development: A social action theoretic analysis. Accounting, Management and Information Technologies. 6, 1-2 (1996), 1-64. DOI:https://doi.org/10.1016/0959-8022(96)00004-5

[21] Bouty Isabelle, Godé Cécile, Drucker Godard Carole, Lièvre Pascal, Nizet Jean, and Pichault François. 2012. Coordination practices in extreme situations. European Management fournal. 30, $6 \quad$ (December 2012), 475-489. DOI:https://doi.org/10.1016/j.emj.2012.03.015

[22] Rita Järventie-Thesleff, Johanna Moisander, and Pikka Maaria Laine. 2011. Organizational dynamics and complexities of corporate brand building - A practice perspective. Scandinavian fournal of Management. 27, 2 (2011), 196-204. DOI:https://doi.org/10.1016/j.scaman.2010.07.001

[23] Catherine Elizabeth Kendig. 2016. What is Proof of Concept Research and how does it Generate Epistemic and Ethical Categories for Future Scientific Practice? Science and Engineering Ethics. 22, 3 (2016), 735-753. DOI:https://doi.org/10.1007/s11948-015-9654-0

[24] Kari Kuutti. 1996. Activity theory as a potential framework for human computer interaction research. In Context and Consciousness: Activity Theory and Human Computer Interaction. MIT Press, 17-44. DOI:https://doi.org/citeulikearticle-id:634717

[25] Antonio Jose Rodrigues Neto. 2004. Um Estudo do Desempenho dos Protocolos iSCSI e Fibre Channel. Universidade de Campinas.
[26] Antonio Jose Rodrigues Neto, Maria Manuel Borges, and Licinio Roque. 2017 Preliminary Study About the Applicability of a Service-Oriented Architecture in the Oais Model Implementation. Proc. 5th International Conference on Technological Ecosystems for Enhancing Multiculturality - TEEM 2017 (2017), 1-5. DOI:https://doi.org/10.1145/3144826.3145381

[27] Antonio Jose Rodrigues Neto, Maria Manuel Borges, and Licinio Roque. 2017. Um estudo preliminar sobre a aplicabilidade da arquitetura orientada a serviços na concretização do modelo OASIS. In A Ciência Aberta - o contributo da Ciência da Informação: atas do VIII Encontro Ibérico EDICIC, 81-92.

28] Antonio Jose Rodrigues Neto and Nelson L S Da Fonseca. 2007. A Comparative Study of the Performance of the Protocols iSCSI and Fiber Channel. In IEEE Latin America Transactions, 150-156. DOI:https://doi.org/10.1109/TLA.2007.4378498

[29] Jay F. Jr. Nunamaker, Minder Chen, and Titus D. M. Purdin. 1990. Systems development in Information Systems Research. Journal of Management Information Systems. 7, 3 (1990), 89-106.

[30] Wanda J. Orlikowski. 1992. The Duality of Technology: Rethinking the Concept of Technology in Organizations. Organization Science. 3, 3 (1992), 398-427. DOI:https://doi.org/10.1287/orsc.3.3.398

[31] Wanda J. Orlikowski and C. Suzanne Iacono. 2001. Research Commentary Desperately Seeking the "IT" in IT Research-A Call to Theorizing the IT Artifact Information System Research. 12, 2 (2001), 121-134.

[32] W.Boyd Rayward. 1996. The history and historiography of information science Some reflections. Information Processing \& Management. 32, 1 (January 1996), 3-17. DOI:https://doi.org/10.1016/0306-4573(95)00046-J

[33] Licinio Roque and Ana Almeida. 2002. The Context Engineering approach: A framework for information systems development. In ICEIS 2002 - Proceedings of the 4th International Conference on Enterprise Information Systems.

[34] Licinio Roque, Ana Almeida, and Antonio Dias de Figueiredo. 2004. Context Engineering: An IS Development Research Agenda. In Proceedings of the 12th European Conference on Information Systems - ECIS 2004, 1582-1595.

[35] Licinio Gomes Roque. 2004. Contribuição para uma Engenharia do Contexto. Universidade de Coimbra.

[36] Tefko Saracevic. 1996. Ciência da informação: origem, evolução e relações. In Perspectiva em Ciência da Informação, 41-62.

[37] Tefko Saracevic. 2000. Interdisciplinary nature of information science Original. Ciência da Informação 24, 1 (2000), 36-41.

[38] Tefko Saracevic. 2009. Information Science. In Encyclopedia of Library and Information Sciences, Third Edition. 2570-2585. DOI:https://doi.org/10.1081/E-ELIS3120043704

[39] Theodore R. Schatzki. 2002. The site of the social: A philosophical account of the constitution of social life and change. The Pennsylvania State University Press.

[40] Theodore R. Schatzki, Karin Knorr Cetina, and Eike Von Savigny. 2001. The Practice Turn in Contemporary Theory. Routledge, London, England.

[41] Bernd Schmidt. 2006. Proof of principle studies. In Epilepsy Research, 49-52. DOI:https://doi.org/10.1016/j.eplepsyres.2005.09.018

[42] Donald A. Schön. 1983. The reflective practitioner: How professionals think in action. Basic Books, New York, USA.

[43] Kleber José da Silva. 2012. Desempenho do protocolo NFSv4 em arquiteturas NAS sob efeito de alterações de parâmetros e da evolução da rede IP. (2012), 112.

[44] H. Simitci, C. Malakapalli, and V. Gunturu. 2001. Evaluation of SCSI over $\mathrm{TCP} / \mathrm{IP}$ and SCSI over fibre channel connections. In HOT 9 Interconnects Symposium on the High Performance Interconnects, 87-91. DOI:https://doi.org/10.1109/HIS.2001.946698

[45] Iúri Batista Teles. 2017. Arcano: Um Sistema de Resposta Pessoal Mobile para Ambientes sem Conexão com a Internet. (2017), 74

[46] Dolf Trieschnigg. 2010. Proof of concept: concept-based biomedical information retrieval. University of Twente.

[47] Etienne Wenger. 1998. Communities of Practice: Learning as a Social System. Systems Thinker. 9, 5 (1998), 2-3. DOI:https://doi.org/10.2277/0521663636

[48] Etienne Wenger. 1998. Community of practice: learning, meaning, and identify. Cambridge University Press. DOI:https://doi.org/10.2277/0521663636

[49] Etienne Wenger, Richard Mcdermott, and William M Snyder. 2002. Cultivating communities of practice: A guide to managing knowledge. Harvard Business Press.

[50] Gernot Wersig. 1993. Information science: The study of postmodern knowledge usage. Information Processing and Management. 29, 2 (1993), 229-239. DOI:https://doi.org/10.1016/0306-4573(93)90006-Y 